American Journal of Pharmacology and Toxicology 3 (1): 44-58, 2008

ISSN 1557-4962

(C) 2008 Science Publications

\title{
Hormesis and Exercise: How the Cell Copes with Oxidative Stress
}

\author{
${ }^{1} \mathrm{Li} \mathrm{Li} \mathrm{Ji},{ }^{2}$ Zsolt Radak and ${ }^{3}$ Sataro Goto \\ ${ }^{1}$ University of Wisconsin-Madison, USA \\ ${ }^{2}$ Semerweis University, Hungary \\ ${ }^{3}$ Tokyo Metropolitan Gerontology Research Institute, Japan
}

\begin{abstract}
Contraction-induced production of reactive oxygen and nitrogen species has been shown to cause oxidative stress to skeletal muscle, heart and other organs. As an adaptive response, muscle antioxidant defense systems are upregulated in response to exercise to restore intracellular prooxidantantioxidant homeostasis. Thus, both young and old animals and humans involved in regular exercise have shown reduced oxidative damage during acute physical exertion at accustomed or excessive intensity, or under oxidative challenges otherwise deemed detrimental. The current article provides a brief review of this exercise-induced hormesis with the emphasis on the role of redox sensitive signal transduction pathways (mainly nuclear factor $\kappa \mathrm{B}$ and mitogen-activated protein kinase) that can activate the gene expression of antioxidant enzymes and proteins. Molecular mechanisms and gene targets for these signaling pathways, as well as the biological significance of the adaptations, are discussed.
\end{abstract}

Key words: Antioxidant, exercise, oxidative stress, reactive oxygen species, signaling

\section{INTRODUCTION}

Maintenance of oxidative -antioxidant homeostasis is critical for cell survival and normal function ${ }^{[1]}$. In the field of free radical biochemistry, one paradox continues to puzzle both researchers and the general public: physical activity demonstrates clear benefit to increase body fitness, prevent disease and improve quality of life, but heavy physical work has been shown to generate reactive oxygen and nitrogen species (RONS), which seriously threaten structural and functional integrity at the cellular, organic and systematic levels. How do we view this paradox scientifically and advise the public properly? Answering this question is a challenging task, as it requires a thorough knowledge about the biochemical role of RONS, their interaction with the biomacromolecules and the relevant physiopathological consequences. Physical exercise involves the entire body in terms of energy metabolism, hormonal mobilization and action, signal transduction process, immunological responses and adaptations. Fortunately, numerous basic and applied scientific researchers have devoted tremendous time and effort during the past quarter century to this topic and accumulated large amount of data to help resolve this puzzle. We recommend readers to consult with a recent special volume of Free Radical Biology and Medicine which will be dedicated to this important field of scientific endeavor.

Hormesis is a pharmacological term meaning low dosage of toxins may increase body's tolerance for greater toxicity ${ }^{[2,3]}$. RONS generated during exercise can cause oxidative stress and damage to skeletal muscle, heart and other organs, but research evidence also demonstrates a critical role of RONS to serve as the chemical agents to maintain cellular milieu and to transfer message to vital cellular components to conduct physiological functions, such as contraction, bioenergetics, growth, proliferation and remodeling (adaptation). Understanding muscle homeostatic response and adaptation to exercise has not only scientific significance but also implications in seeking therapeutic measures to prevent RONS-induced diseases and pathogenic processes such as inflammation, cachesia and sarcopenia. In this article, we will first review research evidence that an acute bout of heavy physical exercise can cause oxidative damage and stress to the body, much like an oxidant drug or toxin does; however, we emphasize that regular (i.e., repeated) exercise reduces exercise-induced oxidative damage with a hormetic effect. The role of cellular antioxidant defense and it adaptation to exercise will be highlighted and the molecular

Corresponding Author: Li Li Ji, The Biodynamics Laboratory, 2000 Observatory Drive, Madison, WI 53706, USA Tel: 608-262-7250 Fax: 608-262-1656 
mechanisms underlying RONS serving as signaling agents will be explored. According to Allen and Trensini ${ }^{[4]}$, cell signaling can influence hormone, cytokine and growth factor modulation; ion channel modulation and ion transport; gene transcription; neuromodulation and apoptosis. Our discussion will focus primarily on cellular adaptation to oxidative stress through gene transcription of antioxidant enzymes although other proteins participating in oxidative damage repair and affecting cellular redox balance will also be touched whenever being relevant. Skeletal muscle will be our primary concern, but heart and liver will also be incorporated to enhance our understanding of how exercise affects the entire body homeostasis.

\section{EXERCISE AND HORMESIS}

Exercise: a cytotoxic agent: Oxidative stress is inevitable in aerobic organisms. The mitochondrial electron transport chain (ETC) system is not perfect in reducing molecular oxygen to water during which the majority of ATP required for cell survival and growth is generated. The process may generate superoxide anion by the reaction of molecular oxygen and electrons leaking out of ETC. The superoxide is quickly converted to hydrogen peroxide by catalysis of mitochondrial Mn-superoxide dismutase (MnSOD). Hydrogen peroxide may be degraded to oxygen and water by mitochondrial glutathione (GSH) peroxidase (GPX). Other sources of superoxide include enzymatic processes such as oxidation of NADPH by NADPH oxidase in stimulated macrophages and neutrophils and oxidation of hypoxanthine and xanthine to uric acid by xanthine oxidase (XO), as well as microsomal electron transport system (cytochrome P-450 reductase). Superoxide generated via non-mitochondrial pathway is converted to hydrogen peroxide by catalysis of CuZnSOD located in the cytosol. There are also enzymatic reactions that generate hydrogen peroxide directly, involving two electron reduction of molecular oxygen, such as amino acid oxidation (D-or L-amino acid oxidase) and glucose oxidation (glucose oxidase). Hydrogen peroxide thus generated can further be transformed into highly reactive hydroxyl radical in non-enzymatic reaction by reduced form of transition metals, i.e., Fe (II) or $\mathrm{Cu}$ (I) (Fenton reaction), or by reduction with superoxide (Harber-Weiss reaction).

Among the reactions generating superoxide mentioned above, mitochondrial ETC, adenine nucleotide catabolism and NADPH oxidase appear to be the major sources in the muscle during exercise. During exercise where ATP consumption is increased by excessive muscle contraction under limited supply of oxygen resembling ischemia, adenine nucleotide catabolism by $\mathrm{XO}$ is enhanced, thus resulting in increased generation of superoxide and hydrogen peroxide. $\mathrm{XO}$ in the capillary is a potential source of $\mathrm{RONS}^{[5]}$. NADPH oxidase complex in the plasma membrane is another potentially source of superoxide that increases during exercise. Damage to the muscle can cause inflammatory reactions attracting macrophages and neutrophils that generate superoxide in the NADPH oxidase catalyzed reaction ${ }^{[6]}$. Muscle damage may cause the release and degradation of myoglobin, a potential source of the catalytic iron. Contracting muscles can consume as much as 100-fold amount of oxygen as compared to resting controls, thus generating massive amount of $\operatorname{RONS}^{[7]}$. This is particularly true during an acute bout of exercise in the unaccustomed muscles ${ }^{[8-11]}$ (Fig. 1). The increased RONS can result in oxidative damage to membrane phospholipids, DNA and proteins ${ }^{[9,10,12]}$. For example, Davies et $a l .^{[8]}$ reported that workload of treadmill running to exhaustion resulted in 2- to 3-fold increase in free radical formation in the skeletal muscle and liver of rats with concomitant increase of lipid peroxidation.

Lipid peroxides are formed by abstraction of hydrogen by hydroxyl and other radicals from unsaturated fatty acid residues of phospholipid in membrane bilayers followed by a sequence of reactions that result in the addition of molecular oxygen to form lipid peroxides. The lipid peroxides are spontaneously cleaved to generate highly reactive aldehydes such as 4hyroxynonenal that can modify proteins and nucleic acids. The fatty acid peroxide ester in phospholipid may be cleaved by phospholipase A2. The peroxidized fatty acids can be reduced by GSH and GPX and a new unsaturated fatty acid is formed thereafter by acyltransferase, with the membrane being fully restored by reacetylation.

The side chains of amino acid residues in proteins may be modified in many different ways by hydroxy radicals generated at or near transition metal binding sites. The modified amino acids include dityrosine from tyrosine, o- or m-tyrosine from phenylalanine, 2oxohistidine from histidine, methionine sulfoxide from methionine, cystine from cysteine and carbonyl derivatives from lysine, arginine, proline and other amino acids ${ }^{[13]}$. Radak et al. ${ }^{[10]}$ showed that an acute bout of treadmill running to exhaustion led to increased protein carbonyl in the lung of rats. Some of these modifications such as those of methionine and cyteine are reversible in vivo and therefore are not necessarily damaging but physiologically useful ${ }^{[14]}$. Apart from the reversible oxidative modifications, the damaged proteins are degraded by proteolytic enzymes. The 


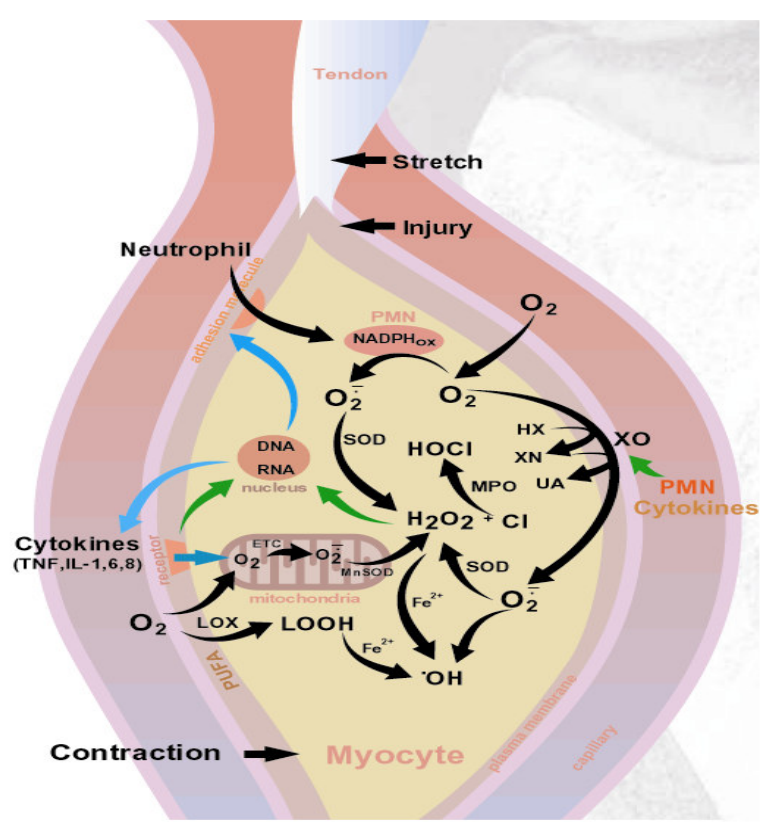

Fig. 1: Sources of Reactive Oxygen Species (ROS) in muscle cells during exercise and contractionmediated injury. ETC, election transport chain; $\mathrm{HOCl}$, hypochorous acid, $\mathrm{HX}$, hypoxanthine, IL, interleukine, LOX, lipooxygenase, MPO, melyeoperoxidase, PMN, polymorphoneutrophil, SOD, superoxide dismutase, TNF- $\alpha$, tumor necrosis factor- $\alpha$, $\mathrm{UA}$, uric acid, $\mathrm{XN}$, xanthine, $\mathrm{XO}$, xanthine oxidase

oxidatively modified proteins may be removed mostly by degradation catalyzed by proteasomes or in some cases by lysosomes. The proteasomes are multicatalytic proteases that degrade altered or regulatory proteins and exist in two forms, $20 \mathrm{~S}$ and $26 \mathrm{~S}$ forms ${ }^{[15]}$. The $26 \mathrm{~S}$ proteasome consisting of $20 \mathrm{~S}$ catalytic core complex plus two 19S regulatory complexes is responsible for the degradation of ubiquitinated proteins, whereas the $20 \mathrm{~S}$ proteasome is involved in the direct degradation of proteins without ubiquitin tags. Both forms are involved in the degradation of oxidatively modified or otherwise altered proteins. As described in the other session the proteasome activity is upregulated by exercise (see Regular Exercise Reduces Oxidative Damage).

There are a number of different oxidative modifications in DNA bases, the most abundant one being 8-hydroxy or 8-oxo guanine ${ }^{[16]}$. The level of the oxidative modification of nuclear DNA is in the order of $10^{-6}$ that may be too low to account for possible functional deteriorations of cells. However, other types of damage such as thymine glycol formation and oxidative deamination of cytosine to uracil in DNA may also occur. The low level of oxidative protein modifications may be more than enough to induce cancer, since a single mutations in 30 billion bases in the human genome can initiate the disease. On the other hand, oxidative modification to mitochondrial DNA is reported to occur at a much higher rate, i.e., several to 10 times more than the rate for nuclear DNA modification ${ }^{[17]}$. In view of the role of mitochondria in cellular energy production, damage to the DNA that codes in part for proteins of the ETC complexes could cause serious functional deterioration of the cell. The modification of DNA bases can be repaired by base excision repair enzyme systems consisting of glycosylase, endonuclease, DNA polymerase and DNA ligase $^{[18]}$. 8-Oxo guanine glycosylase 1 (OGG1) is responsible for the first step repairing 8-oxo guaninecontaining DNA. The activity of OGG1 is increased by exercise (see Regular exercise reduces oxidative damage). The degradation and repair of oxidatively damaged molecules thus constitute an important part of cellular defense systems against oxidative stress, because the antioxidant defense is never perfect, particularly during heavy physical stress or inflammation.

Exercise also has a significant impact on the generation of nitric oxide (NO) from endothelial cells of blood vessels ${ }^{[19]}$. The NO synthase is activated due to increased blood flow that causes shear stress on the vessel wall ${ }^{[20]}$. NO is a vasodilator, controlling blood pressure and serving as an antioxidant at low concentrations. At high concentrations, however, it can react with superoxide to generate highly reactive and cytotoxic peroxynitrite $\left(\mathrm{ONOO}^{-}\right)$. Peroxynitrite can inactivate enzymes and other proteins by modifying tyrosine or thiol of cysteine residues ${ }^{[21,22]}$. Information on the effect of exercise on NO is limited ${ }^{[23]}$, however, it is interesting to note that intensive exercise appears to have no adverse effect on vascular function probably because of the high scavenging capacity of the antioxidant system ${ }^{[24]}$. From the above discussions one may draw a conclusion that unaccustomed exercise (i.e., an exercise intensity that makes the exerciser feel uncomfortable and stressful) may resemble a low level of toxin that imposes detrimental effect to the organisms due to the generation of RONS with their potent cytotoxic reactivity.

Chronic exercise protects against oxidative stress: Exercise training (i.e., regularly scheduled exercise sessions with the same or slightly increased intensity) is known to be beneficial in preventing diseases and improving physiological functions. While an abundance 
of literature is available outlining the effects of training to attenuate oxidative damage in the skeletal muscle and heart ${ }^{[3,7,25,26]}$, recent evidence suggests that the brain could also benefit from regular physical exercise ${ }^{[27,28]}$. For example, swimming training was shown to significantly improve cognitive functions of rats and reduce the oxidative modification of proteins (carbony formation) in the brain ${ }^{[28]}$. Further, the reduction of carbonyl proteins was accompanied by upregulation of the activity of proteasome. The correlation between protein carbonyl and cognitive function was first reported by Carney et al. ${ }^{[29]}$ who found that administration of $\mathrm{N}$-tert-butyl-alpha-phenylnitrone (PBN) decreased age-associated increase in the accumulation of protein carbonyls in the brain of gerbil and improved their short-term memory. The activity of neutral protease located in the proteasome was upregulated, presumably being responsible for the degradation of oxidized proteins. Interestingly, Foster et $a l .{ }^{[30]}$ reported that oxidative damage in brain proteins is negatively correlated with cognitive performance and motor skills in aging mice. The role of exercise in protection of the brain from neurodegenerative disorders has attracted considerable interests from the therapeutic field ${ }^{[31,32]}$. Regular swimming training had similar effects in the skeletal muscle of rats in reducing protein carbonyl of an abundant protein of molecular weight around $29 \mathrm{kDa}$, possibly carbonic anhydrase III, although the level of carbonyl in the total proteins was not significantly affected $^{[33]}$. The 8-oxo dG content of the trained animals was significantly less than the age matched sedentary group. The reduced level of DNA oxidation together with the upregulation of DTdiaphorase $(\mathrm{NAD}(\mathrm{P}) \mathrm{H}$ quinone oxidoreductase), a phase II detoxifying enzyme, were thought to be beneficial in lowering cancer incidence. Reduced DNA oxidation was also found in the liver of rats subjected to regular treadmill running ${ }^{[34]}$. Taken together, it is conceivable that the beneficial outcome of training is likely derived from each exercise session. Recent research suggests that there is a complex interaction during exercise involving RONS, nuclear factor (NF) $\mathrm{kB}$ and brain derived neurotrophic factor leading to the activation of certain signal transduction pathways and upregulation of antioxidant defense system ${ }^{[35]}$.

Hormetic adaptation of antioxidant defense system: There is an abundance of literature reporting muscle antioxidant adaptation to chronic exercise training and several reviews have also addressed this topic thoroughly ${ }^{[36-40]}$. Among antioxidant enzymes in skeletal muscle, SOD activity has been shown to increase with exercise training in an intensitydependent manner ${ }^{[41-43]}$. MnSOD is primarily responsible for the observed increase in SOD activity, whereas CuZn SOD activity is little affected ${ }^{[41-44]}$. GPX activity has also been shown to increase after endurance training by most authors ${ }^{[42-45]}$. Training effect on CAT activity has been inconsistent and controversial ${ }^{[36,47]}$. Muscle fiber type is an important factor in determining whether and how much training can influence antioxidant enzyme activity, reflecting both fiber recruitment patterns during exercise and intrinsic antioxidant capacity within a given fiber [48]. Rigorous swim training was shown to induce myocardial and diaphragm SOD in rats, indicating the adaptation occurs in all cells where RONS may be increased during exercise $^{[49,50]}$.

It is now clear that the observed training adaptation of antioxidant activity is due to altered gene expression, with both mRNA and enzyme protein levels being upregulated. However, data are limited and sometimes controversial. For example, MnSOD activity and protein content were shown to increase with endurance training in several rat muscles, but mRNA level for MnSOD was not affected ${ }^{[51-53]}$. CuZnSOD mRNA level reportedly was elevated with training in rat deep vastus lateralis (DVL) muscle and heart, albeit no change in protein content was seen ${ }^{[54]}$. Since mRNA generally has a short half-life and muscle tissues in the above studies were harvested 24-48 $\mathrm{h}$ post exercise, it can be concluded that mRNA may increase only transiently following acute exercise bouts. In contrast to SOD, our knowledge regarding gene regulation of GPX and CAT is quite limited. Steady state GPX mRNA levels in trained rat muscles are not different from the sedentary controls $^{[54]}$.

In addition to primary antioxidant enzymes, exercise training can upregulate enzymes synthesizing non-enzymatic antioxidants and controlling intracellular redox status thus affecting overall oxidant-antioxidant homeostasis, such as enzymes controlling GSH synthesis and metabolism in the $\gamma$-glutamyl cycle ${ }^{[55]}$. Endurance training has also been shown to increase GSH content in DVL and gastrocnemius in rats and several hindlimb muscles in dogs along with increased $\gamma$-glutamyl transpeptidase (GGT), $\gamma$-glutamylcysteine synthetase (GCS) and glutathione synthetase ${ }^{[56-59]}$. Interestingly, rigorous swimming training caused a decrease of GSH content in rat myocardium ${ }^{[60]}$. These muscle specific responses are probably explained by the fact that soleus and myocardium have 60-70 and 32\% lower GGT and GCS activity, respectively, than DVL. Thus, the oxidation of GSH may far exceed their capacity to import GSH from extracellular source. 
Physically trained human subjects and animals generally demonstrate a greater tolerance of exerciseinduced disturbance of blood GSH. Plasma and erythrocyte GSH contents have been shown to increase significantly after physical training in human ${ }^{[61-63]}$. Like GSH, thioredoxin (TRX) glutaredoxin and peroxiredoxin play an important role in controlling cellular redox status by reducing protein and nonprotein disulfides, removing peroxides and facilitating other cellular functions ${ }^{[64]}$. Recently, the gene expression of thioredoxin reductase, the key enzyme to reduce oxidized TRX, was reportedly elevated in mouse and human blood after an acute bout of exercise ${ }^{[65]}$.

Homeostasis between oxidants and antioxidants is essential for organism survival. Exercise plays an important role in animal evolution because physical mobility is absolutely required for seeking food, escaping from predators and reproduction. Thus, an increase in RONS generation and subsequent oxidative damage during demanding exercise may represent a price to pay for long-term well being as the organism will be more prepared to handle higher level of physical demand and stress. Adaptation of antioxidant defense system holds the key to understanding this hormetic response.

Aging and hormesis: Role of exercise: Aging is associated with progressive accumulation of damaged cellular constituents that can be detrimental or useless for cells if not repaired or replaced by undamaged molecules. Such changes can lead to decline of physiological functions that result in increased probability of diseases and eventual death of an organism. Damage is induced by exposure to internal and external stresses, most notably oxidative stress by RONS that are generated in life maintenance metabolic processes $^{[2]}$. A number of protective networks are operating in cells or extra cellular milieu to maintain homeostasis against harmful oxidative stress, including antioxidants, antioxidant enzymes, chaperons, repair enzymes and degrading enzymes for damaged molecules. Aging may be viewed as deteriorative process of the defense systems that are active enough in youth to escape accumulation of oxidatively damaged molecules but become progressively less active with advancing age. It should, however, be noted that RONS are not always harmful but rather play essential roles for life as mediators of signal transduction and other biological processes ${ }^{[66,67]}$.

Oxidatively modified proteins accumulate with advancing age due to increasing generation of RONS and reduced activities of antioxidant enzymes together with impaired turnover of proteins ${ }^{[68,69]}$. Oxidative damage to DNA is also increased with age in both nucleus and mitochondria ${ }^{[70,71]}$. Oxidatively modified DNA may be repaired by nucleotide and/or base excision repair enzyme systems ${ }^{[72]}$. The decline of the repair activity can cause aging and age-related diseases $^{[73]}$.

The roles of RONS in exercise have been a focus of considerable interests in relation to aging ${ }^{[74-77]}$. Bejma et al. ${ }^{[11,78]}$ reported that free radical generation was significantly higher in skeletal muscle, heart and liver of old rats subjected to an acute bout of treadmill running to exhaustion. The level of TBARS and protein carbonyl was elevated more in old animals. Such consequences are possibly due to reduced antioxidant enzyme activities in sedentary old animals at least in certain tissues in addition to increased generation of RONS with age ${ }^{[79]}$. The result can, however, be different for regular exercise where sufficient time is given for adaptation to upregulate defense systems to cope with oxidative stress even in middle-aged or old animals. In fact, protein carbonyl was reduced by 9 weeks of regular swimming in the brain of 14 monthold rats ${ }^{[28]}$. The proteasome that was upregulated was likely involved in the reduction. Radak et al. ${ }^{[80]}$ reported that two months of regular treadmill running reduced RONS production and increased GSH content in the liver of middle-aged (18 month-old) and old (28 month-old) rats. The regimen attenuated the activation of redox sensitive transcription factor NFKB associated with age in the old rats by preventing the degradation of I $\mathrm{KB}$ alpha, an inhibitory protein for NFkB (see the session Molecular Mechanism of Exercise Induced Hormesis). The attenuation of NFkB via reduced oxidative stress may be a mechanism of anti-inflammatory roles of regular exercise ${ }^{[81,82]}$. A similar regular exercise regimen was found to reduce age-related increase of oxidative modification in nuclear and mitochondrial DNA of the liver of old rats ${ }^{[35]}$. The OGG1 activity was found upregulated in the nucleus but not in mitochondria. The reduction of oxidative modification in nuclear DNA by regular exercise may play a part in explaning well-recognized epidemiological data reporting that physically active people have decreased risk of cancer ${ }^{[83,84]}$. The reduced mitochondrial DNA oxidation may be relevant to antiaging effect of the physical activity in view of roles of deterioration of mitochondria in aging ${ }^{[85]}$.

Death may be considered a final failure of the organism to maintain oxidant-antioxidant homeostasis throughout the life span. Generation of RONS usually leads the race whereas adaptation of antioxidant system tries to catch up and restore balance. Exercise is a double-edged sword, with the one edge increasing 
RONS production and the other edge stimulating the upregulation of antioxidant. To fully assess the role of exercise at a particular stage of life one needs to consider a host of factors including the individual's health status, disease disposure, life style and intensity of exercise. However, the benefit of participating in physical activity is unequivocal and probably exceeds that of the detrimental effects caused by RONS generation, at least prior to the very late stage of life.

\section{MOLECULAR MECHANISM OF EXERCISE- INDUCED HORMESIS}

Exercise can cause wide-spread changes from organelle to the entire body, therefore the mechanism for exercise-induced hormetic effects may also be broad. Previous sections have already touched some potential adaptive mechanisms such as DNA repair and degradation of damaged proteins. The following section will be primarily focused on the adaptation of the cellular antioxidant defense system. Readers are referred to several recent reviews on this topic ${ }^{[3,74,86-88]}$.

General mechanism: There is clear evidence now that RONS can stimulate the gene expression of antioxidant enzymes, immunoactive proteins such as cytokines and chemokines and transcription factors. Among the main pathways are NFKB, MAPK, the phosphoinositide 3kinase $\left(\mathrm{PI}_{3} \mathrm{~K}\right) /$ Akt pathway, p53 activation and the heat shock response ${ }^{[4]}$. A variety of chemical and physical agents are capable of serving as the signaling molecules in response to oxidative stress, such as $\mathrm{H}_{2} \mathrm{O}_{2}, \mathrm{NO}, \mathrm{Ca}^{2+}$ and cytokines. When cells are exposed to UV irradiation, phorboesters, toxins, redox-disturbing agents, growth factors and anoxia/hypoxia/hyeroxia, intracellular levels of the above-mentioned chemical messengers are increased. This may be caused by increased metabolism (such as mitochondrial respiration), inflammation, ion-channel opening, activation of enzymes, or simply chemical reactions. These messengers transfer signals from the cell surface to the nucleus to stimulate gene expression. A glance at the list of potential signaling molecules provided by Allen and Tresini ${ }^{[4]}$ indicates that $\mathrm{H}_{2} \mathrm{O}_{2}$ by far is the most common messenger contributing more than $50 \%$ of the cases. This is not surprising because $\mathrm{H}_{2} \mathrm{O}_{2}$ is constantly produced in the mitochondria during normal metabolism and is a relatively stable but strong oxidant capable of oxidizing a variety of moieties yet not highly destructive. $\mathrm{H}_{2} \mathrm{O}_{2}$ is small enough to defuse across most, but not all, biomembrane barriers ${ }^{[89]}$. Intracellular level of $\mathrm{H}_{2} \mathrm{O}_{2}$ is often elevated in response to other signaling molecules such as cytokines ${ }^{[00]}$.
The molecular mechanism for RONS to induce antioxidants lies mainly on the interactions between gene regulatory sequences on antioxidant gene, usually, but not always in the promoter region and the transcription factors. RONS can influence the activity of transcription factor binding through several ways. (1) RONS may active kinases so as to trigger a signaling cascade through sequential enzyme phosphorylation such as the MAPK hierarchies ${ }^{[4]}$, (2) RONS may modulate phosphatase activity controlled by a critical cysteine residues sensitive to redox status ${ }^{[00]}$, (3) RONS may regulate the synthesis and degradation of transcription factors thereby determining their concentration and/or ability to form homodimer or heterodimer; (4) Cellular reductant levels and redox status play an important role in the regulation of antioxidant signaling. The most significant cellular sources of reductants are GSH and thioredoxin (Trx) ${ }^{[91]}$. When intracellular GSH/GSSG ratio is decreased, critical thiols located on the active site of key enzymes can be oxidized forming intra- or inter-protein disulfide. This may attenuate signaling capacity. Trx is involved in the reduction of cysteine residues in the oxidativelymodified proteins and is known to modulate p50/P65 binding to $\kappa \mathrm{B}$ sequence in the target gene promoter ${ }^{[92]}$.

Exercise activation of redox signaling pathways: NFKB and MAPK are considered the most critical for the cells to cope with oxidative stress and distinct signaling pathways in the cell ${ }^{[4]}$. NFkB is primarily responsive to stress, toxins and cytokines leading to inflammation, apoptosis and adaptation, whereas the primary consequence of MAPK activation is growth, development, transcription, translation and remodeling. However, there are considerable crosstalks between the two pathways ${ }^{[93]}$. This interaction appears to be critical in conferring antioxidant adaptation to exercise ${ }^{[86]}$.

MAPK has a complicated hierarchy including extracellular signal-regulated kinase (ERK), c-Jun amino-terminal kinase $(\mathrm{JNK})$ and $\mathrm{p} 38^{\mathrm{MAPK}}$, which are regulated by their respective upstream kinases MKK and $\mathrm{MEKK}^{[4]}$. MAPK activation was first reported in rat skeletal muscle after an acute bout of treadmill running ${ }^{[94]}$. p42- and p44 ${ }^{\mathrm{MAPK}}$ (i.e., ERK1/2) were also shown to be phosphorylated after bicycle exercise in human muscle, along with activation of MEK1 and Raf-1 (MEKK), as well as downstream substrate p90 ribosomal S6 kinase $(\mathrm{RSK})^{[95]}$. Since then, numerous studies have shown that MAPK signal transduction pathways can be activated by contractile activity in skeletal muscle $\mathrm{e}^{[96-100]}$. The signals triggering the MAPK activation have been attributed to a variety of physiological stimuli associated with exercise including 
hormones, calcium ion, neural activity and mechanical force. Biological implications of MAPK activation are wide-spread including such important functions as glucose transport, muscle and heart hypertrophy, angiogenesis and vascular adaptation ${ }^{[101-103]}$. Interestingly, prior training status in the animals and human subjects demonstrated a strong influence on the activation patterns such that training tended to attenuate the activation intensity of several MAPK enzymes $^{[98,104,105]}$.

$\mathrm{NFKB}$ complexes are present in the cytoplasm in an inactive state, conjugated with the inhibitory IкB protein ${ }^{[106]}$. NFkB is activated by a variety of external stimulants, such as $\mathrm{H}_{2} \mathrm{O}_{2}$, pro-inflammatory cytokines (TNFo, IL-1, IL-6), lipopolysaccharide (LPS) and phorbol esters. These signals are believed to activate IKB kinase (IKK) through the activation of NFKBinducing kinase (NIK), a family of $\mathrm{MEKK}^{[107,108]}$, or activation of a member of the protein kinase $\mathrm{C}$ family $(\mathrm{PKC} \zeta)^{[92]}$. Phosphorylation of two serine residues of I $\kappa \mathrm{B}$ leads to $\mathrm{I} \kappa \mathrm{B}$ ubiquitination and proteolytic degradation by the $26 \mathrm{~S}$ proteasome. IKB dissociation unleashes the P50/P65 subunits of NFKB to translocate into the nucleus and bind the DNA sequence of the gene targets. The best-known proteins and enzymes that require consensus binding of $\mathrm{KB}$ in the promoter are MnSOD, GCS, inducible NOS (iNOS), cyclooxygenase-2 (COX-2), vascular cell adhesion molecule-1 (VCAM-1) and several cytokines. These genes are involved in a wide variety of biological functions such as antioxidant defense, inflammation, immunity, anti-apoptosis ${ }^{[109,110]}$.

AP-1 is another important transcription factor composed of activating (c-Fos and c-Jun) and inhibitory (Fos-related antigen [Fra]-1 and 2) subunits ${ }^{[111]}$. Depending on the cellular redox milieu and cell type, Fos and Jun can dimerize or interact with other transcription factors leading to activation or inhibition of gene transcription of antioxidant and immunoactive proteins ${ }^{[112,113]}$. Recent research suggests that AP-1 function is also dependent on MAPK and NFKB signaling pathways ${ }^{[111]}$.

Hollander et al. ${ }^{[114]}$ first reported that $\mathrm{NFKB}$ and AP-1 bindings were elevated in rat skeletal muscle after an acute bout of prolonged exercise in a fiber-specific manner. The increased NFKB and AP-1 binding was accompanied by increased MnSOD mRNA abundance and protein content in exercised muscle. Ji et al. ${ }^{[15]}$ showed that NFKB binding in rat DVL muscle was increased after exercise, along with increased IKK activity, I $\mathrm{KB} \alpha$ phosphorylation and degradation and nuclear P50 accumulation. The exercise-induced activation of NFKB was attenuated by pyrrolidine dithiocarbamate (PDTC) and was mimicked by LPS, whereas t-butylhydroperoxide treatment had little effect on $\mathrm{NFKB}$, indicating that the signaling was induced by specific chemical agents rather than general oxidative stress. Ho et al. ${ }^{[116]}$ reported that NFKB activation was elevated two-fold in the soleus (type 1) and red gastrocnemius (type 2a) muscles during $60 \mathrm{~min}$ of treadmill exercise in rats, accompanied by IKK $\alpha / \beta$ phosphoralation. Application of p38 and ERK inhibitors reduced IKK $\alpha / \beta$ activation, suggesting MAPK and NFKB may work synergistically during exercise.

Gene targets of redox signaling: Most antioxidant enzymes contain gene regulatory sequences in their promoter and intron regions that can interact with redox-sensitive transcription factors to trigger upregulation of gene expression ${ }^{[4]}$. Because of the widespread implications of RONS in almost all important biological functions, it is difficult to define all the pathways and gene targets that are affected by redox signaling during exercise. The following are some of the most relevant products that play a critical role in homeostatic regulation of muscle oxidative-antioxidant balance (Fig. 2).

Mn SOD is a well-known target gene for NFKB activation and its expression has been shown to be upregulated by an acute bout of exercise ${ }^{[51-54,117]}$. The MnSOD promoter contains NFKB and AP-1 binding sites and its upregulation by $\mathrm{TNF} \alpha$ and $\mathrm{IL}-1$ is mediated in part by NFKB activation ${ }^{[118,119]}$. Recently, it has been shown that MnSOD can be activated by platelet-derived growth factor (PDGF) due to early growth-responsive-1 (egr-1) protein binding to a putative GC-rich region of MnSOD gene, which may be controlled by MEK1 and ERK1/2 signaling ${ }^{[120]}$. TNF $\alpha$, IL-1 and PMA have been shown to upregulate MnSOD gene through a complex intronic enhancer sequence binding involving NFKB, CCAAT-enhancer binding protein $(\mathrm{C} / \mathrm{EBP}), \mathrm{Sp}-1$ and nuclear factor (NF)- $1^{[121,122]}$. P65 translocation and binding was found to be essential for MnSOD transactivation ${ }^{[123]}$. GomezCabrera et al. ${ }^{[117]}$ showed that ERK1/2 and p38 were activated in rat gastrocnemius muscle after an acute bout of intense treadmill running, accompanied with a two-fold increase in MnSOD mRNA level. Injection of allopurinol, a xanthing oxidase inhibitor, abolished exercise-induced ERK and p38 activation and MnSOD upregulation, suggesting that cytosolic source of RONS may be involved in MnSOD signaling. 
Am. J. Pharm. \& Toxicol., 3 (1): 44-58, 2008

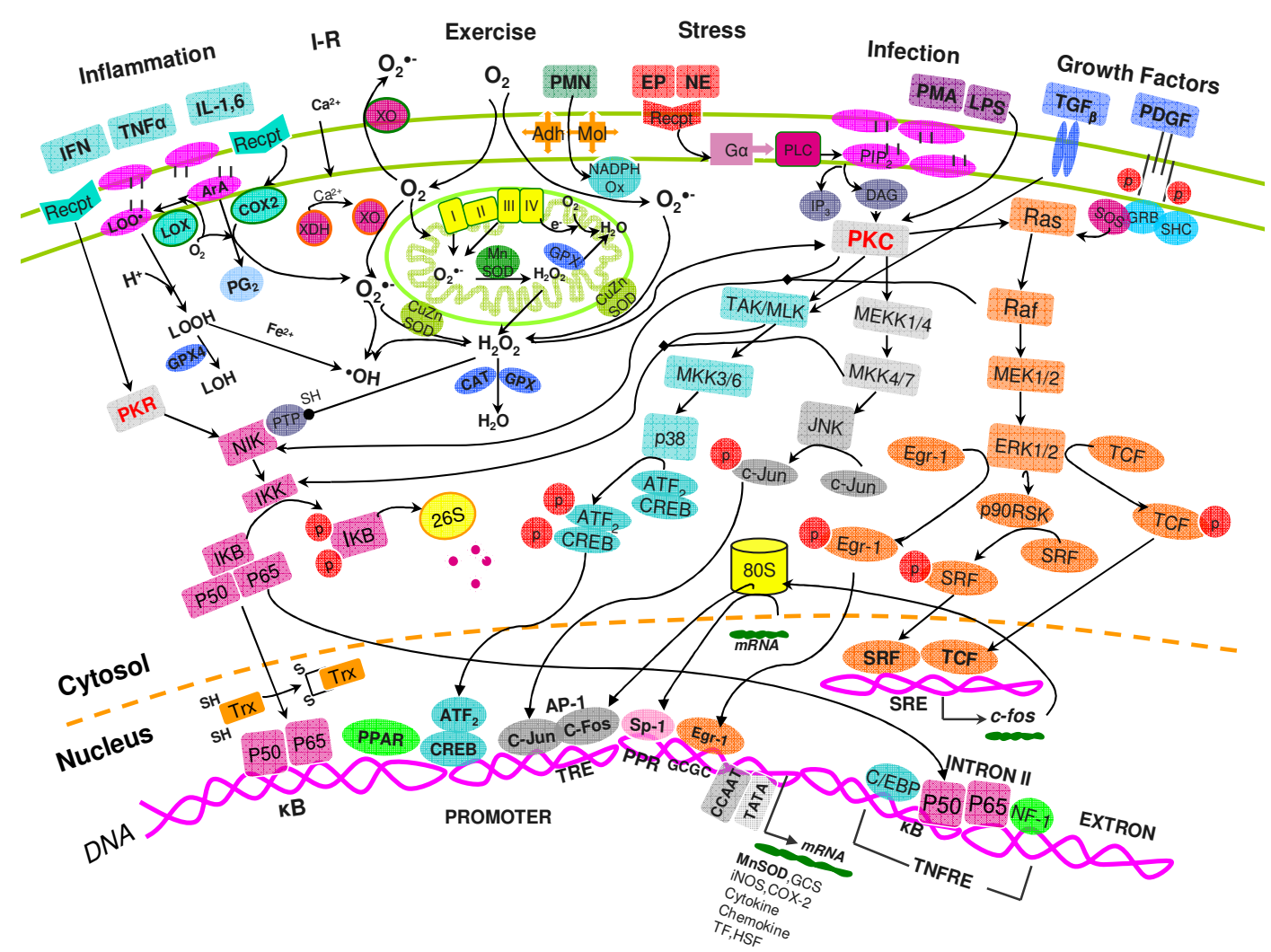

Fig. 2: Schematic illustration of redox signaling pathways based on current understanding primarily of, but not limited to, MnSOD gene regulation. Also shown are the major sources of ROS generation in the cell in response to physiological stimuli, and cellular antioxidant defense systems. The illustration did not intend to include all components and pathways of redox signaling, but those mentioned in the text. There may be substantial differences between different cell types. Abbreviations used are: 26S, proteasome 26S. 80S, ribosome. Adh Mol, adhesion molecule. ArA, arachidonic acid. ARE, antioxidant response element. $\mathrm{ATF}_{2}$, activating transcription factor-2. C/EBP, CCAAT enhancer binding protein. COX-2, cyclooxygenase-2. CRE, cAMP-response element. DAG, diacylglycerol. Egr-1, early growth-responsive-1 protein. EP, epinephrine. Ga, G-protein. $\alpha$ subunit. GPX, glutathione peroxidase. IFN, interferon. $\mathrm{IP}_{3}$, inositol triphosphate. $\mathrm{IP}_{3}$, inositol 3-phosphate. I-R, ischemia-reperfusion. $\mathrm{LOOH}$, lipoperoxide. $\mathrm{LOH}$, hydroxylipid. LOX, lipooxygenase. MLK, mixed lineage kinases. NE, norepinephrine. NF-1, nuclear factor1. $\mathrm{PG}_{2}$, prostaglandin 2. $\mathrm{PIP}_{2}$, phosphotidylinositol. P90RSK, p90 ribosomal S6 kinase. PLC, phospholipase C. PMN, polymorphoneutrophil. PPAR, perosisome proliferator-activated receptor. PPR, proximal promoter region. SRE, serum response element. PTP, tyronsine phosphatases. SRF, serum response factor. TAK, transforming growth factor $\beta$-activated kinase. TCF, ternary complex factor. $\mathrm{TGF}_{\beta}$, transforming growth factor $\beta$. TRE, tetradecanoylphorbolacetate response element. TNFRE, TNF $\alpha$ response element. XO, xanthine oxidase

An acute bout of exercise has been shown to activate CuZnSOD activity, but most studies reported no change in its mRNA and enzyme protein levels suggesting the increased activity is due to posttranslational control. However, Radak et al. ${ }^{[124]}$ showed that enzyme activity and protein content of both $\mathrm{CuZn}$ and Mn SOD in rat soleus and tibialis muscles were elevated after a single bout of treadmill running lasting 60-70 min. CuZnSOD promoter contains an AP2 binding site has been reported to play a role in the upreguation of CuZnSOD by phytopanaxadiol $\mathrm{Rb}_{2}$ (a ginsenoside fraction) ${ }^{[125]}$. Yoo et al. ${ }^{[126]}$ showed that the hydrogen peroxide-responsive element (HRE) on the promoter was responsible for the activation of 
CuZnSOD gene expression by $\mathrm{H}_{2} \mathrm{O}_{2}$, paraquat and heat shock in human Hep2 cells. Little is known about the effect of exercise on the redox signaling of CuZnSOD.

GPX is a homotetramer with each $22-\mathrm{kDa}$ subunit bound to a selenium atom existing as a selenocysteine $^{[1,127]}$. The expression of the GPX gene, hgpx1, occurs in a wide range of tissues controlled by development, hormones and oxygen tension. In the myocardium, GPX activity induced by oxygen tension was found to be proportional to the mRNA levels, suggesting a transcriptional mechanism ${ }^{[128]}$. GPX promoter contains both $\mathrm{NFKB}$ and $\mathrm{AP}-1$ binding sites. Zhou et al. ${ }^{[129]}$ showed that $\mathrm{H}_{2} \mathrm{O}_{2}$ and paraquat-induced GPX mRNA expression in $\mathrm{C} 2 \mathrm{C} 12$ cell culture was dependent on functional NFKB signaling. Introduction of an I $\kappa \mathrm{B}$ mutant abolished GPX mRNA expression. In addition, two oxygen response elements (ORE) located at -1232 to -1213 and -282 to -275 in the 5'-flanking region of human GPX gene have been identified ${ }^{[127]}$. Franco et al. [130] reported a 4-5 fold increase in GPX mRNA level in cultured myotubes in response to paraquat, $\mathrm{H}_{2} \mathrm{O}_{2}$ and menadione treatment. Clerch et al. ${ }^{[131]}$ showed that a common protein in rat lung might bind to both GPX and Mn SOD mRNA thereby increasing their stability, suggesting a posttranscriptional regulation. Whether the abovementioned mechanisms play a role in training-induced GPX activity is unknown.

NOS NO at low concentration exerts an antioxidant function by neutralizing $\mathrm{O}_{2}^{-\bullet}$. Its vasodilative effect increases blood flow to working muscle thereby improving the availability of blood-borne energy substrates and antioxidants ${ }^{[132]}$. Unlike the other forms of NOS, iNOS is not regulated by $\mathrm{Ca}^{2+}$ but induced primarily by RONS and inflammatory cytokines through activation of $\mathrm{NFKB}$ and $\mathrm{MAPK}^{[133]}$. In rat skeletal muscle myoblasts, the IL- $1 \beta$-mediated iNOS induction was reduced by blocking ERK1/2 activation and completely abolished by the inhibition of NFKB. Increased iNOS mRNA level after an acute bout of exercise in rat skeletal muscles has been reported by some authors ${ }^{[117,132]}$, but not others ${ }^{[134]}$. However, the role of iNOS is controversial because it is often coexpressed with pro-inflammatory cytokines and adhesion molecules causing muscle inflammation and wasting. High levels of NO production also leads to the formation of peroxynitrite, a highly reactive species contributing to muscle oxidative damage.

\section{SUMMARY AND PERSPECTIVE}

RONS generated during muscle contraction can significantly change cell prooxidant-antioxidant balance (homeostasis) resulting in specific oxidative damage to the various cell components. Misuse and disuse of muscle may also cause or amplify RONS production which underlies etiology of certain muscular disease and aging. However, RONS also play a critical role in muscle adaptation to exercise-induced oxidative stress by activating redox-sensitive signal transduction of antioxidant enzymes and other proteins vital to cell survival and functionality. Thus, we propose that exercise has a hormetic effect wherein chronic lowdose exposure can result in increased tolerance to a higher level of stress, no matter the stress is physical, mental, pathological, or environmental. Needless to say, when RONS production far exceeds the ability of the cell to adapt through hormesis, crisis could occur leading to apoptosis or even cell death. Fig. 3 is a schematic illustration of these complex relationships existing within the muscle. Disturbance and disruption of such regulatory pathways may result in adverse effects on cell function and survival.

Exercise is a complex biological activity challenging homeostasis at the cell, tissue, organ and whole body levels and demands acute adjustment as well as long-term adaptation to cope with the potential stress $^{[135]}$. We still know very little about the molecular nature of these adjustments and adaptations. Our research has been largely focused on the role of RONS, without concerning other potentially important physiological factors such as nerve activity, ion channel and mechanical force. This review also is limited to hormetic effect on antioxidant system leaving a wide range of other benefits of exercise untouched. We hope our work will stimulate broader and more fruitful research in this intriguing field of science.

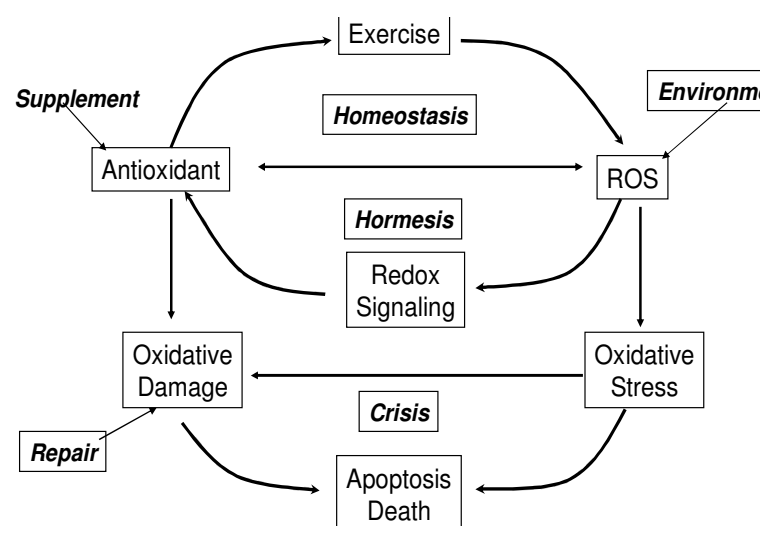

Fig. 3: The proposed role of exercise-induced hormesis in cell adaptation and survival 


\section{REFERENCES}

1. Halliwell, B. and J.M.C. Gutteridge, 1989. Free Radicals in Biology and Medicine. Oxford: Clarendon Press.

2. Finkel, T. and N. Holbrook, 2000. Oxidants, oxidative stress and the biology of ageing. Nature, 408: 239-247.

3. Radak, Z., H.Y. Chung and S. Goto, 2005. Exercise and hormesis: Oxidative stress-related adaptation for successful aging. Biogerontol., 6: 71-75.

4. Allen, R.G. and M. Tresini, 2000. Oxidative stress and gene regulation. Free. Radic. Biol. Med., 28: 463-499.

5. Duarte, J.A., H.J. Appell, F. Carvalho, M.L. Bastos and J.M. Soares, 1993. Endothelium-derived oxidative stress may contribute to exercise-induced muscle damage. Int. J. Sports Med., 14: 440-443.

6. Suzuki, K., H. Sato, T. Kikuchi, T. Abe, S. Nakaji, K. Sugawara, M. Totsuka, K. Sato and K. Yamaya, 1996. Capacity of circulating neutrophils to produce reactive oxygen species after exhaustive exercise. J. Appl. Physiol., 81: 1213-1222.

7. Ji, L.L., C. Leeuwenburgh, S. Leichtweis, M. Gore, R. Fiebig, J. Hollander and J. Bejma, 1998. Oxidative stress and aging. Role of exercise and its influences on antioxidant systems. Ann. N. Y. Acad. Sci., 854: 102-117.

8. Davies, K.J., A.T. Quintanilha, G.A. Brooks and L. Packer, 1982. Free radicals and tissue damage produced by exercise. Biochem. Biophys. Res. Commun., 107: 1198-205

9. Alessio, H.M., A.H. Goldfarb and R.G. Cutler, 1988. MDA content increases in fast- and slowtwitch skeletal muscle with intensity of exercise in a rat. Am. J. Physiol., 255: C874-877.

10. Radak, Z., A. Nakamura, H. Nakamoto, K. Asano, H. Ohno and S. Goto, 1998. A period of anaerobic exercise increases the accumulation of reactive carbonyl derivatives in the lungs of rats. Pflugers Arch., 435: 439-441

11. Bejma, J. and L.L. Ji, 1999. Aging and acute exercise enhance free radical generation in rat skeletal muscle. J. Appl. Physiol., 87: 465-470

12. Radak, Z., K. Asano, M. Inoue, T. Kizaki, S. Oh-Ishi, K. Suzuki, N. Taniguchi and H. Ohno, 1996. Superoxide dismutase derivative prevents oxidative damage in liver and kidney of rats induced by exhausting exercise. Eur. J. Appl. Physiol. Occup. Physiol., 72: 189-194.

13. Stadman, E.R. and R.L. Levine, 2003. Free radicalmediated oxidation of free amino acids and amino acid residues in proteins. Amino. Acids, 25: 207-218.
14. Stadman, E.R., J. Moskovitz and R.L. Levine, 2003. Oxidation of methionine residues of proteins: Biological consequences. Antioxid. Redox Signal., 5: 577-582.

15. Liu, J., H.C. Yeo, E. Overvik-Douki, T. Hagen, S.J. Doniger, D.W. Chyu, G.A. Brooks and B.N. Ames, 2000. Chronically and acutely exercised rats: Biomarkers of oxidative stress and endogenous antioxidants. J. Appl. Physiol., 89: 21-28.

16. Martinez, G.R., A.P. Loureiro, S.A. Marques, S. Miyamoto, L.F. Yamaguchi, J. Onuki, E.A. Almeida, C.C. Garcia, L.F. Barbosa, M.H. Medeiros and P. Di Mascio, 2003. Oxidative and alkylating damage in DNA. Mutat Res., 544: 115-127.

17. Barja, G. and A. Herrero, 2000. Oxidative damage to mitochondrial DNA is inversely related to maximum life span in the heart and brain of mammals. FASEB J., 214: 312-318.

18. Russo, M.T., G. De Luca, P. Degan and M. Bignami, 2007. Different DNA repair strategies to combat the threat from 8-oxoguanine. Mutat. Res., 614: 69-76.

19. Maiorana, A., G. O'Driscoll, R. Taylor and D. Green, 2003. Exercise and the nitric oxide vasodilator system. Sports Med., 33: 1013-1035.

20. Kojda, G. and R. Hambrecht, 2005. Molecular mechanisms of vascular adaptations to exercise. Physical activity as an effective antioxidant therapy? Cardiovasc. Res., 67: 187-197.

21. Gorg, B., N. Qvartskhava, P. Voss, T. Grune, D. Haussinger and F. Schliess, 2007. Reversible inhibition of mammalian glutamine synthetase by tyrosine nitration. FEBS Lett., 581: 84-90.

22. Sethuraman, M., N. Clavreul, H. Huang, M.E. McComb, C.E. Costello and R.A. Cohen, 2007. Quantification of oxidative posttranslational modifications of cysteine thiols of p21ras associated with redox modulation of activity using isotope-coded affinity tags and mass spectrometry. Free Radic. Biol. Med., 42: 823-829.

23. McAllister, R.M. and M.H. Laughlin, 2006. Vascular nitric oxide: Effects of physical activity, importance for health. Essays Biochem., 42: 119-131.

24. Goto, C., Y. Higashi, M. Kimura, K. Noma, K. Hara, K. Nakagawa, M. Kawamura, K. Chayama, M. Yoshizumi and I. Nara, 2003. Effect of different intensities of exercise on endothelium-dependent vasodilation in humans: role of endothelium-dependent nitric oxide and oxidative stress. Circulation, 108: 530-535. 
25. Haskell, W.L., I.M. Lee, R.R. Pate, K.E. Powell, S.N. Blair, B.A. Franklin, C.A. Macera, G.W. Heath, P.D. Thompson and A. Bauman, 2007. Physical activity and public health: Updated recommendation for adults from the American College of Sports Medicine and the American Heart Association. Med. Sci. Sports Exerc., 39: 1423-1434.

26. Powers, S.K. and D. Criswell, 1996. Adaptive strategies of respiratory muscles in response to endurance exercise. Med. Sci. Sports Exerc., 28: $1115-1122$.

27. Kiraly, M.A. and S.J. Kiraly, 2005. The effect of exercise on hippocampal integrity: Review of recent research. Int. J. Psychiatry Med., 35: 75-89.

28. Radak, Z., T. Kaneko, S. Tahara, H. Nakamoto, J. Pucsok, M. Sasvari, C. Nyakas and S. Goto, 2001. Regular exercise improves cognitive function and decreases oxidative damage in rat brain. Neurochem Int. 38: 17-23.

29. Carney, J.M., P.E. Starke-Reed, C.N. Oliver, R.W. Landum, M.S. Cheng, J.F. Wu and R.A. Floyd, 1991. Reversal of age-related increase in brain protein oxidation, decrease in enzyme activity and loss in temporal and spatial memory by chronic administration of the spin-trapping compound N-tert-butyl-alpha-phenylnitrone. Proc. Natl. Acad. Sci. USA, 88: 3633-3636.

30. Forster, M.J., A. Dubey, K.M. Dawson, W.A. Stutts, H. Lal and R.S. Sohal, 1996. Agerelated losses of cognitive function and motor skills in mice are associated with oxidative protein damage in the brain. Proc. Natl. Acad. Sci. USA, 93: 4765-4769.

31. Cotman, C.W., N.C. Berchtold and L.A. Christie, 2007. Exercise builds brain health: Key roles of growth factor cascades and inflammation. Trends Neurosci., 30: 464-472.

32. Gomez-Pinilla, F., 2007. The influences of diet and exercise on mental health through hormesis. Ageing Res. Rev., 2007 May 5, [Epub ahead of print].

33. Radak, Z., T. Kaneko, S. Tahara, H. Nakamoto, H. Ohno, M. Sasvari, C. Nyakas and S. Goto, 1999. The effect of exercise training on oxidative damage of lipids, proteins and DNA in rat skeletal muscle: Evidence for beneficial outcomes. Free Radic. Biol. Med., 27: 69-74.

34. Nakamoto, H., T. Kaneko, S. Tahara, E. Hayashi, H. Naito, Z. Radak and S. Goto, 2007. Regular exercise reduces 8-oxodG in the nuclear and mitochondrial DNA and modulates the DNA repair activity in the liver of old rats. Exp. Gerontol., 42: 287-295.
35. Marini, A.M., H. Jiang, H. Pan, X. Wu and R.H. Lipsky, 2007. Hormesis: A promising strategy to sustain endogenous neuronal survival pathways against neurodegenerative disorders. Ageing Res. Rev., [Epub ahead of print].

36. Jenkins, R.R., 1988. Free radical chemistry: Relationship to exercise. Sport Med., 5: 156-170.

37. Meydani, M. and W.J. Evans, 1993. Free radicals, exercise and aging. Yu, B.P. (Ed.): Free Radical in Aging. Boca Raton: CRC Press, pp: 183-204.

38. Ji, L.L., 1995. Exercise and oxidative stress: Role of the cellular antioxidant systems. Exerc. Sport Sci. Rev., 23: 135-166.

39. Sen, C.K., 1995. Oxidants and antioxidants in exercise. J. Appl. Physiol., 79: 675-86.

40. Reid, M.B., 2001. Redox modulation of skeletal muscle contraction: What we know and what we don't. J. Appl. Physiol., 90: 724-731.

41. Higuchi, M., L.J. Cartier, M. Chen and J.O. Holluszy, 1985. Superoxide dismutase and catalase in skeletal muscle: Adaptive response to exercise. J. Gerontol., 40: 281-286.

42. Leewenburgh, C.R., R. Fiebig, R. Chandwaney and L.L. Ji, 1994. Aging and exercise training in skeletal muscle: Responses of glutathione and antioxidant enzyme systems. Am. J. Physiol., 267: R439-R445.

43. Powers, S.K., D. Criswell, J. Lawler, L.L. Ji, D. Martin, R.A. Herb and G. Dudley, 1994. Influence of exercise and fiber type on antioxidant enzyme activity in rat skeletal muscle. Am. J. Physiol., 266: R375-R380.

44. Ji, L.L., F.W. Stratman and H.A. Lardy, 1988. Antioxidant enzyme systems in rat liver and skeletal muscle: Influences of selenium deficiency, chronic training and acute exercise. Arch. Biochem. Biophys., 263: 150-60.

45. Ji, L.L., F.W. Stratman and H.A. Lardy, 1988. Enzymatic downregulation with exercise in rat skeletal muscle. Arch. Biochem. Biophys., 263: 137-149.

46. Laughlin, M.H., T. Simpson, W. L.Sexton, O.R. Brown, J.K. Smith and R.J. Korthuis, 1990. Skeletal muscle oxidative capacity, antioxidant enzymes and exercise training. J. Appl. Physiol., 68: 2337-2343.

47. Quintanilha, A.T., 1984. The effect of physical exercise and/or Vitamin $\mathrm{E}$ on tissue oxidative metabolism. Biochem. Soc. Trans., 12: 403-404.

48. Lawler, J.M., S.K. Powers, T. Visser, H. Van Dijk, M.J. Kordus and L.L. Ji, 1993. Acute exercise and skeletal muscle antioxidant and metabolic enzymes: Effect of fiber type and age. Am. J. Physiol., 265: R1344-R1350. 
49. Powers, S.K., D. Criswell, J. Lawler, D. Martin, F.K. Lieu, L.L. Ji and R.A. Herb, 1993. Rigorous exercise training increases superoxide dismutase activity in the ventricular myocardium. Am. J. Physiol., 265: H2094-2098.

50. Powers, S.K., D. Criswell, J. Lawler, D.Martin, L.L. Ji, and G. Dudley, 1994. Training-induced oxidative and antioxidant enzyme activity in the diaphragm: Influence of exercise intensity and duration. Resp. Physiol., 95: 226-237.

51. Ohno, H., K. Suzuki, J. Fujii, H. Yamashita, T. Kizaki, S. Oh-ishi and N. Taniguchi, 1994. Superoxide Dismutases in Exercise and Disease, in Exercise and Oxygen Toxicity. Sen, C.K., L. Packer, O. Hanninen (Eds.). New York, Elsevier Science, pp: 127-161.

52. Oh-ishi, S., T. Kizaki, J. Nagasawa, T. Izawa, T. Komabayashi, N. Nagata, K. Suzuki, N. Taniguchi and H. Ohno, 1997. Effects of endurance training on superoxide dismutase activity, content and mRNA expression in rat muscle. Clin. Exp. Pharmacol. Physiol., 24: 326-332.

53. Hollander, J., R. Fiebig, M. Gore, J. Bejma, T. Ookawara, H. Ohno and L.L. Ji, 1999. Superoxide dismutase gene expression in skeletal muscle: Fiber-specific adaptation to endurance training. Am. J. Physiol., 277: R856-R862.

54. Gore, M., R. Fiebig, J. Hollander, M. Griffiths, C. Leeuwenburgh, H. Ohno and L.L. Ji, 1998. Exercise training alters antioxidant enzyme gene expression in rat skeletal muscle. Can. J. Physiol. Pharmacol., 76: 1139-1145.

55. Ji, L.L. and C. Leeuwenburgh, 1995. Exercise and Glutathione. In: Pharmocology in Exercise and Sports. Somani, S. (Ed.). CRC Press, Boca Raton. Florida, pp: 97-123.

56. Leeuwenburgh, C., J. Hollander, S. Leichtweis, M. Griffiths, M. Gore and L.L. Ji, 1997. Adaptations of glutathione antioxidant system to endurance training are tissue and muscle fiber specific. Am. J. Physiol., 272: R363-R369.

57. Sen, C.K., E. Marin, M. Kretzschmar and O. Hanninen, 1992. Skeletal muscle and liver glutathione homeostasis in response to training, exercise and immobilization. J. Appl. Physiol., 73: 1265-1272.

58. Marin, E., M. Kretzschmar, J. Arokoski, O. Hanninen and W. Klinger, 1993. Enzymes of glutathione synthesis in dog skeletal muscle and their response to training. Acta Physiol. Scand., 147: 369-73.
59. Ramires, P. and L.L. Ji, 2001. Glutathione supplementation and training increases myocardial resistance to ischemia-reperfusion in vivo. Am. J. Physiol., 281: H679-H688.

60. Leichtweis, S.C., Leeuwenburgh, R. Chandwaney and L.L. Ji, 1997. Rigorous swim training impaires mitochondrial function in rat heart. Acta. Physiol. Scand., 160: 139-148.

61. Robertson, J.D., R.J. Maughan, G.G. Duthie and P.C. Morrice, 1991. Increased blood antioxidant systems of runners in response to training. Clin. Sci., 80: 611-618.

62. Evelo, C.T.A., N.G. Palmen, Y. Artur and G.M.E. Janssen, 1992. Changes in blood glutathione concentrations and in erythrocyte glutathione reductase and glutathione $\mathrm{S}$-transferase activity after running training and after participation in contests. Eur. J. Appl. Physiol., 64: 354-358.

63. Kretzschmar, M., U. Pfeifer, G. Machnik and W. Klinger, 1991. Influence of age, training and acute physical exercise on plasma glutathione and lipid peroxidation in man. Inter. J. Sports Med., 12: 218-222.

64. Haddad, J.J., 2002. The involvement of L-gammaglutamyl-L-cysteinyl-glycine (glutathione/GSH) in the mechanism of redox signaling mediating MAPK(p38)-dependent regulation of proinflammatory cytokine production. Biochem. Pharmacol., 63:305-320.

65. Sumida, S., H. Nakamura and J. Yodoi, 2004. Thioredoxin induction of peripheral blood mononuclear cells in mice in response to a single bout of swimming exercise. Gen. Physiol. Biophys., 23: 241-249.

66. Linnane, A.W., M. Kios and L. Vitetta, 2007. Healthy aging: Regulation of the metabolome by cellular redox modulation and prooxidant signaling systems: The essential roles of superoxide anion and hydrogen peroxide. Biogerontol., 8: 445-467.

67. Lambeth, J.D., 2007. Nox enzymes, ROS and chronic disease: An example of antagonistic pleiotropy. Free Radic. Biol. Med., 43: 332-347.

68. Levine, R.L. and E.R. Stadtman, 2001. Oxidative modification of proteins during aging Exp Gerontol., 36: 1495-1502.

69. Goto, S., R. Takahashi, A.A. Kumiyama, Z. Radak, T. Hayashi, M. Takenouchi and R. Abe, 2001. Implications of protein degradation in aging. Ann. N. Y. Acad. Sci., 928: 54-64.

70. Shigenaga, M.K., T.M. Hagen and B.N. Ames, 1994. Oxidative damage and mitochondrial decay in aging. Proc. Natl. Acad. Sci. USA, 91: 10771-10778. 
71. Lombard, D.B., K.F. Chua, R. Mostoslavsky, S. Franco, M. Gostissa and F.W. Alt, 2005. DNA repair, genome stability and aging. Cell, 120: 497-512.

72. Barnes, D.E. and T. Lindahl, 2004. Repair and genetic consequences of endogenous DNA base damage in mammalian cells. Annu. Rev. Genet., 38: 445-476.

73. Bohr, V.A., 2002. Repair of oxidative DNA damage in nuclear and mitochondrial DNA and some changes with aging in mammalian cells. Free Radic. Biol. Med., 32: 804-312.

74. Ji, L.L., 2007. Antioxidant signaling in skeletal muscle: A brief review. Exp. Gerontol., 42: 582-593.

75. Judge, S. and C. Leeuwenburgh, 2007. Cardiac mitochondrial bioenergetics, oxidative stress and aging. Am. J. Physiol. Cell Physiol., 292: C1983-1992.

76. Goto, S., Z. Radak, C. Nyakas, H.Y. Chung, H. Naito, R. Takahashi, H. Nakamoto and R. Abe, 2004. Regular exercise: an effective means to reduce oxidative stress in old rats. Ann. N. Y. Acad. Sci., 1019: 471-474.

77. Yu, B.P. and H.Y. Chung, 2006. Adaptive mechanisms to oxidative stress during aging. Mech. Ageing Dev., 127: 436-443.

78. Bejma, J., P. Ramires and L.L. Ji, 2000. Free radical generation and oxidative stress with ageing and exercise: Differential effects in the myocardium and liver. Acta Physiol. Scand, 169: 343-351.

79. Ji, L.L., 1993. Antioxidant enzyme response to exercise and aging. Med. Sci. Sports Exerc., 25: 225-231.

80. Radák, Z., H.Y. Chung, H. Naito, R. Takahashi, K.J. Jung, H.J. Kim and S. Goto, 2004. Ageassociated increase in oxidative stress and nuclear transcription factor NF-kB activation are attenuated in rat liver by regular exercise. FASEB. J., 18: 749-750.

81. Pedersen, B.K., 2006. The anti-inflammatory effect of exercise: Its role in diabetes and cardiovascular disease control. Essays Biochem., 42: 105-117.

82. Bruunsgaard, H., 2005. Physical activity and modulation of systemic low-level inflammation. J. Leukoc Biol., 78: 819-835.

83. Blair, S.N., H.W. Kohl, 3rd, R.S. Paffenbarger, Jr, D.G. Clark, K.H. Cooper and L.W. Gibbons, 1989. Physical fitness and all-cause mortality. A prospective study of healthy men and women. JAMA., 262: 2395-2401.
84. Voskuil, D.W., E.M. Monninkhof, S.G. Elias, F.A. Vlems and F.E. van Leeuwen, 2007. Task Force Physical Activity and Cancer. Physical activity and endometrial cancer risk, a systematic review of current evidence. Cancer Epidemiol. Biomarkers Prev., 16: 639-648.

85. Balaban, R.S., S. Nemoto and T. Finkel, 2005. Mitochondria, oxidants and aging. Cell, 120: 483-495

86. Ji, L.L. 2008 Modulation of Skeletal Muscle Antioxidant Defense by Exercise: Role of Redox Signaling. Free Radic. Biol. Med. 44: 142-152

87. Reid, M., 2007. Redox regulation of muscle fatigue. J. Appl. Physiol., (In press).

88. Powers, S.K. and M.J. Jackson, Exercise-induced oxidative stress: cellular mechanisms and impact on muscle force production. Physiol. Rev., (In press).

89. Chance, B., H. Sies and A. Boveris, 1979. Hydroperoxide metabolism in mammalian organs. Physiol. Rev., 59: 527-605.

90. Meyer, M., H.L. Pahl and P.A. Baeuerle, 1994. Regulation of the transcription factors NF-kB and AP-1 by redox changes. Chemico-Biol. Interact., 91: 91-100.

91. Monteiro, H.P. and A. Stern, 1996. Redox modulation of tyrosine phosphorylation-dependent signal transduction pathways. Free Radic. Biol. Med., 21: 323-333.

92. Flohé, L., R. Brigelius-Flohé, C. Saliou, M. Traber and L. Packer, 1997. Redox regulation of NFKappa B Activation. Free Radic. Biol. Med., 22: 1115-1126.

93. Carroll, M.P. and W.S. May, 1994. Protein kinase C-mediated serine phosphorylation directly activates Raf-1 in murine hematopoietic cells. J. Biol. Chem., 269: 1249-1256.

94. Goodyear, L., P. Chang, D. Sherwood, S. Dufresne and D. Moller, 1996. Effects of exercise and insulin on mitogen-activated protein kinase signaling pathways in rat skeletal muscle. Am. J. Physiol., 271: E403-E408.

95. Aronson, D., M.A. Violan, S.D. Dufresne, D. Zangen, R.A. Fielding and L.J. Goodyear, 1997. Exercise stimulates the mitogen-activated protein kinase pathway in human skeletal muscle. J. Clin. Invest., 99: 1251-1257.

96. Ryder, J., R. Fahlman, H. Wallberg-Henriksson, D. Alessi, A. Krook and J. Zierath, 2000. Effect of contraction on mitogen-activated protein kinase signal transduction in skeletal muscle. J. Biol. Chem., 275: 1457-1462. 
97. Baar, K. and K. Esser, 1999. Phosphorylation of $\mathrm{P} 70^{\mathrm{S} 6 \mathrm{~K}}$ correlates with increased skeletal muscle mass following resistance exercise. Am. J. Physiol. Cell Physiol., 276: C 120-C127.

98. Nader, G. and K. Esser, 2001. Intracellular signaling specificity in skeletal muscle in response to different modes of exercise. J. Appl. Physiol., 90: 1936-1942.

99. van Ginneken, M.M., E. de Graaf-Roelfsema, H.A. Keizer, K.G. van Dam, I.D. Wijnberg, J.H. van der Kolk and E. van Breda, 2006. Effect of exercise on activation of the p38 mitogenactivated protein kinase pathway, c-Jun $\mathrm{NH} 2$ terminal kinase and heat shock protein 27 in equine skeletal muscle. Am. J. Vet. Res., 67: 837-844.

100.Coffey, V.G., Z. Zhong, A. Shield, B.J. Canny, A.V. Chibalin, J.R. Zierath and J.A. Hawley, 2006. Early signaling responses to divergent exercise stimuli in skeletal muscle from well-trained humans. FASEB. J., 20: 190-192.

101.Long, Y.C., U. Widegren and J.R. Zierath, 2004. Exercise-induced mitogen-activated protein kinase signalling in skeletal muscle. Proc. Nutr. Soc., 63: 227-232.

102.Hawley, J.A. and J.R. Zierath, 2004. Integration of metabolic and mitogenic signal transduction in skeletal muscle. Sport Sci. Rev., 32: 4-8.

103.Sakamoto, K. and L.J. Goodyear, 2002. Invited review: Intracellular signaling in contracting skeletal muscle. J. Appl. Physiol., 93: 369-383.

104.Boluyt, M.O., A.M. Loyd, M.H. Roth, M.J. Randall and E.Y. Song, 2003. Activation of JNK in rat heart by exercise: Effect of training. Am. J. Physiol. Heart Circ. Physiol., 285: H2639-47.

105.Iemitsu, M., S. Maeda, S. Jesmin, T. Otsuki, Y. Kasuya and T. Miyauchi, 2006. Activation pattern of MAPK signaling in the hearts of trained and untrained rats following a single bout of exercise. J. Appl. Physiol., 101: 151-163.

106. Baeuerle, P.A. and D. Baltimore, 1988. Activation of DNA-binding activity in an apparently cytoplasmic precursor of the NFKB transcriptiona factor. Cell, 53: 211-217.

107.Li, N. and M. Karin, 1999. Is NFKB the sensor of oxidative stress? FASEB. J., 13: 1137-1143.

108.Li, Q. and J.F. Engelhardt, 2006. Interlecukin-1 $\beta$ induction of $\mathrm{NF \kappa B}$ is partially regulated by $\mathrm{H}_{2} \mathrm{O}_{2-}$ mediated activation of NFKB-inducing kinase. J. Biol. Chem., 281: 1495-1505.

109.Ghosh, S., M.J. May and E.B. Kopp, 1998. NFkappa B and Rel proteins: evolutionarily conserved mediators of immune responses. Annu. Rev. Immunol., 16: 225-260.
110.Ghosh, S. and M. Karin, 2002. Missing pieces in the NF-kappaB puzzle. Cell., 109 (Suppl): S81-96.

111.Catani, M.V., I. Savini, G. Duranti, D. Caporossi, R. Ceci, S. Sabatini and L. Avigliano, 2004. Nuclear factor kappaB and activating protein 1 are involved in differentiation-related resistance to oxidative stress in skeletal muscle cells. Free. Radic. Biol. Med., 37: 1024-1036.

112.Bergelson, S., R. Pinkus and V. Daniel, 1994. Induction of AP-1 (Fos/Jun) by chemical agents mediates activation of glutathione S-transferase and quinone reductase gene expression. Oncogene. 9: $565-571$.

113.Sekhar, K.R., M.J. Meredith, L.D. Kerr, S.R. Soltaninassab, D.R. Spitz, Z.Q. Xu and M.L. Freeman, 1997. Expression of glutathione and gamma-glutamylcysteine synthetase mRNA is Jun dependent. Biochem. Biophys. Res. Commun., 234: 588-593.

114.Hollander, J., R. Fiebig, T. Ookawara, H. Ohno and L.L. Ji, 2001. Superoxide dismutate gene expression is activated by a single bout of exercise. Pflug. Arch. Eur. J. Physiol., 442: 426-434.

115.Ji, L.L., M.C. Gomez-Cabrera, N. Steinhafel and J. Vina, 2004. Acute Exercise Activates Nuclear Factor (NF) $\kappa B$ Signaling Pathway in Rat Skeletal Muscle. FASEB. J., 18: 1499-1506.

116.Ho, R.C., M.F. Hirshman, Y. Li, D. Cai, J.R. Farmer, W.G. Aschenbach, C.A. Witczak, S.E. Shoelson and L.J. Goodyear, 2005. Regulation of IkappaB kinase and NF-kappaB in contracting adult rat skeletal muscle. Am. J. Physiol. Cell Physiol., 289: C794-801.

117.Gomez-Cabrera, M.C., C. Borras, F.V. Pallardó, J. Sastre, L.L. Ji and J. Vina, 2005. Decreasing xanthine oxidase mediated oxidative stress prevents useful cellular adatptations to exercise in rats. J. Physiol., (London) 567: 113-120.

118.Ho, Y.S., A.J. Howard and J.D. Crapo, 1991. Molecular structure of a functional rat gene for manganese-containing superoxide dismutase. Am. J. Respir. Cell. Molec. Biol., 4: 278-286.

119.Das, K.C., Y. Lewis-Molock and C.W. White, 1995. Thiol modulation of TNF alpha and IL-1 induced MnSOD gene expression and activation of NF-kappa B. Mol. Cell Biochem., 148: 45-57.

120.Maehara, K., K. Oh-Hashi and K.I. Isobe, 2001. Early growth-responsive-1-dependent manganese superoxide dismutase gene transcript mediated by platelet-derived growth factor. FASEB. J., 15: 2025-2026. 
121.Kininggham, K.K., Y. Xu, C. Daosukho, B. Popova and D. St. Clair, 2001. Nuclear Factor $\kappa \mathrm{B}$-dependent mechanism coordinate the synergistic effect of PMA and cytokines on the induction of superoxide dismutase 2. Biochem. J., 353: 147-156.

122.Maehara, K., T. Hasegawa and K.I. Isobe, 2000. A NF-kappaB p65 subunit is indispensable for activating manganese superoxide: Dismutase gene transcription mediated by tumor necrosis factoralpha. J. Cell Biochem., 77: 474-486.

123.Guo, Z., H. Boekhoudt and J.M. Boss, 2003. Role of the intronic enhancer in tumor necrosis factormediated induction of manganous superoxide dismutase. J. Biol. Chem., 278: 23570-23578.

124.Radak, Z., K. Asano, M. Inoue, T. Kizaki, S. Oh-Ishi, K. Suzuki, N. Taniguchi and H. Ohno, 1995. Superoxide dismutase derivative reduces oxidative damage in skeletal muscle of rats during exhaustive exercise. J. Appl. Physiol., 79: 129-135.

125.Kim, Y.H., K.H. Park and H.M. Rho, 1996. Transcriptional Activation of the $\mathrm{Cu}, \mathrm{Zn}$ Superoxide Dismutase Gene through the AP2 Site by Ginsenoside Rb2 extracted from a medicinal plant, Panax ginseng. J. Biol. Chem., 271: 4539-24543.

126.Yoo, H.Y., M.S. Chang and H.M. Rho, 1999. The activation of the rat copper/zinc superoxide dismutase gene by hydrogen peroxide through the hydrogen peroxide-responsive element and by paraquat and heat shock through the same heat shock element. J. Biol. Chem., 274: 23887-23892.

127.Cowan, D.B., R.D. Weisel, W.G. Williams and D.A.G. Mickle, 1993. Identification of oxygen responsive elements in the 5-flanking region of the human glutathione peroxidase gene. J. Biol. Chem., 268: 26904-26910.

128. Cowan, D.B., R.D. Weisel, W.G. Williams and D.A.G. Mickle, 1992. The regulation of glutathione peroxidase gene expression by oxygen tension in cultured human cardiomyocytes. J. Mol. Cell. Cardiol., 24: 423-433.
129.Zhou, L.Z., A.P. Johnson and T.A. Rando, 2001. NF kappa B and AP-1 mediate transcriptional responses to oxidative stress in skeletal muscle cells. Free Radic. Biol. Med., 31: 1405-1416.

130.Franco, A.A., R.S. Odom and T.A. Rando, 1999. Regulation of antioxidant enzyme gene expression in response to oxidative stress and during differentiation of mouse skeletal muscle. Free Radic. Biol. Med., 27: 1122-1132.

131.Clerch, L., A. Wright and D.J. Chung, 1996. Evidence that glutathione peroxidase RNA and manganese superoxide dismutase RNA bind the same protein. Biochem. Biophys. Res. Commun., 222: 590-594.

132.Balon, T.W., 1999. Integrative biology of nitric oxide and exercise. Exerc Sport Sci. Rev., 27: 219-253.

133.Adams, V., B. Nehrhoff, U. Spate, A. Linke, P.C. Schulze, A. Baur, S. Gielen, R. Hambrecht and G. Schuler, 2002. Induction of iNOS expression in skeletal muscle by IL-1beta and NFkappaB activation: an in vitro and in vivo study. Cardiovasc. Res., 54: 95-104.

134. Vassilakopoulos, T., G. Deckman, M. Kebbewar, G. Rallis, R. Harfouche and S.N. Hussain, 2003. Regulation of nitric oxide production in limb and ventilatory muscles during chronic exercise training. Am. J. Physiol. Lung Cell Mol. Physiol., 284: L452-L457.

135.Zieker, D., E. Fehrenbach, J. Dietzsch, J. Fliegner, M. Waidmann, K. Nieselt, P. Gebicke-Haerter, R. Spanagel, P. Simon, A.M. Niess and H. Northoff, 2005. cDNA microarray analysis reveals novel candidate genes expressed in human peripheral blood following exhaustive exercise. Physiol. Genomics, 23: 287-294. 